\title{
Government Governance of Smart Cities in China
}

\author{
Sun GaoAng1,a \\ ${ }^{1}$ School of Management, Guangdong Ocean University, Haida Road, Huguang Town, Mazhang \\ District, Guangdong Province, China \\ asungaoang@hotmail.com
}

Keywords: smart city, government governance, urbanization strategy, cybersecurity

\begin{abstract}
China, as one of the most modern countries in Asia, has played a vital role in developing domestics smart cities since the government has been mainly promoting the urbanization strategy for years in order to achieve the highest urbanization growth rate as well as the vast space for development in the future. Before carrying out the plan of smart cities, the government has conducted a lot of researchs on how to construct the domestics smart cities. Thus, based on the practical situation in China, the government decided to develop diverse strategies in different cities. It is no doubt that the general development is successful while the problems are obvious as well. Therefore, the issues that lack the cybersecurity, the funding gap, as well as the lack of overall planning, should be concerned.
\end{abstract}

\section{Introduction}

There is no denying that it is necessary to construct the smart cities in China since the smart cities are the fundamental purpose for the city development. The countries in Europe can be an excellent example for the government to learn from the smart city. Later China created the plan of the domestics' smart city in Dec 2012 [1]. The provisional administrative measures for national smart city pilot program set out the eligibility for enrolling in the project of smart city strategy in China. Hence, 2012 was the application submission period. And after several years, the construction of a smart city has been improved a lot. In 2016, the state put forward a new style of smart cities and started on the selfassessment exercise on the new style.

What should be the focus on here is the main challenges for the government to deal with now. For instance, lack of overall planning, the deficiencies represent in information security as well as the funding gap. Thus, according to these challenges, the effective solutions which can be carried out are the core of this essay, and they will be mentioned below.

\subsection{The definition of smart city}

According to Techopedia, a smart city is a designation given to a city that incorporates information and communication technologies (ICT) to enhance the quality and performance of urban services such as energy, transportation, and utilities in order to reduce resource consumption, wastage and overall costs. And the overall aim of a smart city is to improve the quality of citizen's lives through smart technology [5].

Refer to the definition history of smart city, it is showed by IBM in November 2008. After the economic crisis, cities across Asian countries are eager to get rid of the economic downturn. IBM combines the concept of "smart planet" with urban management and actively Recommended by local governments. The "Smart Earth" concept provided inspiration for public planning scholars and then proposed the concept of "Smart City".

\subsection{The characteristics of smart city}

There are several characteristics of the smart city. For instance, stylish housing is the prerequisite in the smart city. Smart housing means reasonable consumption. According to the estimation, the smart building solution saves approximately $30 \%$ of energy consumption for each building. Secondly, urban mobility is the apparent feature as well. One of the typical examples of urban mobility is the parking system. The smart parking system can save the city $\$ 50$ million of parking costs annually. Thirdly, 
municipal water and urban energy are the representative traits. The smart system of urban energy and water can save at least $9-14 \%$ of the fuel cost, and carbon emission can be expected to reduce by $40 \%$ by 2025 . At the same time, the water is estimated to be saved $\$ 58$ million annually [5].

\subsection{The current situation of smart city in China}

There is no denying that the development of the smart city has experienced several stages. From the beginning of 2012.12, the National Smart City Pilot Program was started in China and the application submission period commenced. And now, the pattern pf smart city is continuously improved. The state proposed a new style of smart city and started the self-assessment exercise on the new style.

According to the latest data, the current phenomenon of the smart city in China is that the cities develop their key program according to the city's economy and living style. For example, for Beijing, the main task in the whole smart city strategy is big data and the smart economy. To illustrate, in Beijing, the widespread broadband facilities and smart IT-based applications promote the development of information technology and construction in the capital city and boost the economy. Meanwhile, the bid data and the growing economy are what Beijing needs now.

However, Wuhan, which is another key city in China, is not suitable for developing big data and economic growth. Wuhan is a living city with a peaceful atmosphere and a slow pace. Hence, enhancing interaction between the government and the public and improve the standard of living by efficient transmission and the intelligent response of the city's information. Smart living is a genuine demand for Wuhan.

So, the core task for the smart city strategy is diverse based on the current situation and the demand for different cities.

\subsection{The future trend of smart city in China}

It is no doubt that the future trend of smart city has been concerned by the public now. Except for the smart housing, urban water and energy, urban mobility, the smart economy, smart education, and smart safety will be the core to develop and to be the future trend.

Smart economy means the advanced technologies can help the government to improve the management procedures, such as approval and licensing. Meanwhile, digitization and big data analytics can improve the urban manager's capability in tracking performance and outcomes.

Thus, the economy can be grown rapidly and efficiently. And smart safety can be described that the drones, wearable computing facial recognition can be used to maintain public safety. And the crime recording can be trapped in the social and crowdsourced data. Besides, the secure data platform, transparent governance, and smart access protocols help ensure that data is safe.

Last but not least, smart education refers to visual learning, digitalization and augmented reality transform learning approach. The personalized which can be designed by the traits of each child can be successful by using the rich data and analytics. The focus is that learning in the classroom will be shifted into real-world learning.

\section{The experience on governance of smart cities in China}

The practical orientation of smart city government governance should be based on the government's macro guidance, combined with smart city government governance, considered by society and market demand, integrating urban macro-planning and urban development needs, and comprehensive consideration. The government has the leading role in the whole project of the smart cities. And based on different situations of the cities, the means and the roles will be changed as well.

\subsection{Strategic planners of smart cities}

From the beginning, the government is the leader to guide the construction of the smart city project. On the basis of using the new generation of information technology, an institutional and operational framework are set up and through the establishment of preferential policies conducive to smart city strategy. To facilitate urban construction; promote the construction of standards and information security systems, and provide a scientific evaluation system for supervising the construction of smart 
cities, in order to correct the development direction of smart cities. At the same time, the government, as the strategic planner of the whole program, it should decide the overall construction strategy of different countries based on the traits of the cities. Since some cities should develop the technology while others may promote the hard facilities.

For example, the strategy of smart cities in Shanghai and Guangzhou is different. For Shanghai, the core task is the advanced information technology and smart infrastructure. There is no denying that Shanghai is the leading city in the eastern part of China. Hence, it is necessary to strengthen the information infrastructure and cybersecurity as well as promoting the real-time collection of data of public transportation. So that the whole operation speed of Shanghai can be fastened and the efficiency will be improved as well. At the same time, it can lead to the practical operation of other cities around. While, Guangzhou, the core task is the smart transport only. The smart transportation sensor platform covers core districts, primary and secondary trunk roads, and city entrances and exists to achieve real-time monitoring and control on the passenger traffic volume and flow at passenger transportation hubs.

\subsection{Government-market-coordinator of social relations}

Except for the guidance, the tie of social relations is another role the government has acted. What the government should do is to balance the relationship among all fields.

In the mechanism of urban governance and the control of the organization, it has broken through traditional linear thinking and coordinated the balance of urban management systems with the idea of large system integration. The smart city government firstly handles the relationship between the government and the market and promotes the direction of urban development with market demand. In addition, by handling the relationship between the government and the society, especially the relationship between the government and the people's livelihood, the city provides public goods to the public, so that the public can enjoy social welfare and social security, and upgrade the level of urban smart management practices. The smart city not only uses the rational intelligence of the machine but also combines it with human emotions to enhance the level of humanized intelligent service.

Meanwhile, from the perspective of system theory, the government promotes a good relationship between the two, by promoting a balance between the urban economic system and the social activity system. The essence of the smart city government governance public service platform is the interdepartmental coordination platform. By establishing a public service platform characterized by the participation of multiple public management departments and the social grassroots democratic model in which the pluralistic entities participate, the society provides the public services to the general public. In other words, the relationship in the social activity system has been relaxed. For example, smart urban mobility has solved the parking problems. It has saved at least $\$ 58$ million every year and enlarged more open space for car parking. At the same time, the big data and advanced technology make the economic system move faster and more efficiency. In the end, the genuine profit has been achieved by the public.

\section{The challenges of the development of smart cities in China}

There is no denying that an abundance challenges are met for the government in the process of smart city development.

The biggest challenges are the lack of overall planning. It is the common knowledge that the strategic planning of different cities and different department are different because of the diverse current phenomenon of the individual cities. At first, the benefit is obvious since the development of the individual cities is rapid since all the core problems of the cities can be solved. But in the long term, the shortage can be seen because it leads to varying levels and progress of construction of smart cities. The gap between the neighbor cities will be bigger and bigger so that the distribution of the resources between cities will be unbalanced as well. Above all, the core challenge between neighboring cities is the lack of a long-term overall development blueprint.

The second obvious challenge is the deficiencies in information security. It is no doubt that the 
connection among users, applications, and data increases continuously so that the cybersecurity risk has been increased day by day. At the same time, a large number of users increase the difficulty of cybersecurity management. Hence, the government should collect the data continuously and design the new plan to protect cybersecurity. At the same time, more talented people whose profession is network and high technology should be applied for the certain department of the government. And it is essential to make smart strategies include concepts related to cybersecurity.

Last but not least, the funding gap is the challenge that can't be avoided. All the smart construction needs a surplus of currency. And the construction cost is borne by the government, resulting in substantial financial pressure. In other words, it is the big financial pressure for the government to afford the fund to construct the smart cities altogether. Even, the fund that some cities need is much more than the other cities. Meanwhile, the funding should be involved in human resources since adequate regulation is the base to guarantee the quality and the development of construction.

\section{Promoting the path of government governance in smart cities in China}

\subsection{Strengthen top-level design, innovate and reconstruct the overall planning}

There is no denying that the challenges which have been mentioned above are the shortage of current planning on smart city strategy. It is common in China to meet the challenges now since this is the first time for the government to construct smart cities. Hence, it is vital to devise planning according to challenges now.

Based on the first challenge, the overall planning is the shortage of the whole planning now although the separate planning of the individual cities is outstanding. Hence, it is necessary to design the overall planning as soon as possible.

For the overall planning, the relationship of the neighbor cities is the key factor for the government to consider the planning. There is no denying that the neighbor cities should have a harmonious relationship so that the individual development can be successful. In order to have a harmonious relationship, the balanced resources and funding are the prerequisites. If the gap of resources and funding is much more serious, the battle of the resources may start and the cities will focus on the resources robbing instead of constructing the smart cities. So, the goal of optimizing resource allocation through the coordination of administrative organization structure should be involved in overall planning.

Except for the harmonious relationship, the close relationship should develop as well. To illustrate, the tight relationship means the mutual share of public resources. It is no doubt that superior resources are limited now. And sometimes, the resource allocation will be unbalanced so that one of the most effective approaches is to share the resources with the neighbor cities. So that the cities can develop rapidly together. For instance, the big data system is the core resource in Shanghai and it can be shared with the neighboring cities, Suzhou which focuses on smart living. And the big data can help promote the smart living in Suzhou as well as rising the citizen's living standards. However, to some extent, it is difficult for the cities themselves to develop harmonious relationships and share the resources. At this time, the central government can work as a general conductor. It is the conductor to make the resources of the neighboring cities balanced as well as sharing the capital. At the same time, assisting the regional government is another vital task. Moreover, the regional government should play an important role as well. To illustrate, under the guidance of the central government, the regional government should communicate and cooperate with each other. The final aim for the cooperation is to assign the agreement and make the regional cooperation come true.

The harmonious relationship and the close relationship are the necessary and vital factor to make the overall planning for the government.

\subsection{Improve the cybersecurity of ICT professional management and optimize the function of smart city public service platform}

The smart city is a huge systematic project. Through the design of ICT professional management system and operation mechanism, a unified macro-common standard is established for smart city. 
And all the information can be collected together in the system. Meanwhile, it is the database for the operation of big data.

However, the cybersecurity has been the risk which can't be avoided since there is plenty of information in the system. Hence, the safety protection of the ICT management system should be conducted as soon as possible in case the attack from the hacker and lose the important information. And the professional staff on the network are needed largely to protect the system together.

Besides, in concrete practice, building a smart city public service platform is essential, unify integration and mobilize innovative resources within the city, and uniformly deploy major projects. Actually, the main function of the public service platform is to integrate various existing information systems, propose innovative urban information functions and structure construction due to the diverse regional characteristics and economic development level of each city, and realize the modernization of urban governance. At the same time, the public service platform can work as the communication facilitates to exchange the resources and information. And it will lead citizens with a more efficient and convenient lifestyle, the connection efficiency between the citizens and the various components within the system is improved, and the civic life is "smart". Last but not least, it is also the platform for government and citizens to communicate with each other. And it is convenient for government to take in the effective advice to help construct the smart cities.

\subsection{Broaden the source of funds and improve the infrastructure construction of smart cities}

In the whole project of smart city, the government, enterprises and individuals are all the targets of smart city service and the main builder. And there is a surplus of fields that should be constructed in order to make the smart cities completely. The investment of national and local financial funds in the construction of smart cities should be increased since every field need fund to construct. For instance, in order to have the smart water system, the pollution waster system which can deal with the sewage more efficiently based on the high technology. And the smart sewage system will cost a lot and this is one of the areas that will cost fund. Hence, it is essential to increase the source of funds, except for the national taxes, it is necessary to fully respect the role of market mechanisms, encourage social capital to participate in various forms, including the investment from the foreign enterprise and from the private enterprise. The government funds should cooperate with the social funds.

Meanwhile, a funding platform can be created as well. In the platform, a large amount of progress information of the construction can be revealed on the platform to attract the individual investment from the public. And the scope of the pledge loan for income rights can be expanded, and the stateowned assets and land resources of the city can be used as collateral mortgage guarantees to provide loan support.

However, if all the areas of smart cities can't be conducted at the same time. The government should have a choice. It should focus on investing in high-tech areas, such as big data. Since the big data can be the base to develop other areas such as the advanced systems. Big data can help to collect the data and analyze whether it is possible to develop a certain system. At the same time, big data can be shared with the neighbor cities. So, the high-tech area is deserved to be invested first.

There is no denying that smart cities belong to the public. Since make more people and enterprises involve is the correct way to expand resources and capital.

\section{Summary}

There is no denying that the term, smart city is a new project in China. It is also the future in China. It is obvious for the government, enterprises and individuals to enjoy the benefits which have brought from the smart city strategy, the potential risks are still the problems we should face and try our best to solve. Now, the core point of the smart city strategy is to develop the smart city by their own based on the current situation, and later all the smart cities will cooperate with each other and establish the smart city network which is the final goal for the smart city strategy. 


\section{Acknowledgement}

I would like to express my special thanks of gratitude to my parents, classmates as well as my teachers who have given me the golden opportunity to do this wonderful project on the topic (Government Governance of Smart Cities in China), which also helped me in doing a lot of Research and I came to know about so many new things. Thanks for everyone who has supported me in the process of paper writing.

\section{About the author}

Sun GaoAng was in Zhoukou, Henan on June $16^{\text {th }}, 1999$. He is the Junior in the major of Public Service Management which belongs to School of Management, Guangdong Ocean University.

In the campus, he is the Assistant of Communist Youth League Secretary and the Director of Youth League Office. Meanwhile, he is the formal representative of Student Congress and the head of Public Delegation. During the winter and summer vocation, he worked as the Assistant of Secretary of Business in Business Bureau in Shangqiu, Zhoukou. He also worked as the Assistant of Catain in Business Inspection Brigade in Shangqiu, Zhoukou. Moreover, two articles have been published, one is The Analysis on Management Pattern of Involuntary Immigrant Community-in Zhanjiang Economic Development zone, the other is The Analysis of Happiness Influence for the Interaction among Hosts and Tourists in Island Tourism Community. And now, he is researching the hot issues in the field of social events.

Mr. Sun has been awarded the Outstanding Student in the first Indigo. Leadership Plan and the Top Ten Cadres in Haibin Campus, Guangdong Ocean University.

\section{Reference}

[1]C.Harrison,B.Eckman,R.Hamilton,P.Hartswick,J.Kalagnanam,J.Paraszczak,P.Williams, Foundations for Smarter Cities, IBM Journal of Research and Development, vol. 2, pp18-20, 2010.

[2]Washburn D,Sindhu U, Helping CIOs Understand Smart City Initiatives, Journal of Women $s$ Health, vol. 1, pp45-47, 2010.

[3]Giffinger R,Fertner C,Kramar H,Kalasek R,Pichler-Milanovic N,Meijers E. (2007). Smart cities Ranking of European Medium-Sized cities. [online]. Available: http://www.smart-cities.eu.

[4]Giffinger,et al. (2007). Smart cities-Ranking of European Medium-Sized Cities. [online]. Available: http://www.smart-cities.eu/.

[5]Schaffers H,Komninos N,Pallot M,,Oliveira A.et al, Smart Cities and the Future Internet:Towards Cooperation Frame-works for Innovation, The Future Internet, vol. 3, pp11-16, 2011.

[6]Caragliu,A,Del Bo,C,Nijkamp,P, Smart Cities in Europe, Journal of Women s Health, vol. 17, pp56-57, 2009.

[7]Caragliu A,Del Bo C,Nijkamp P. (2009). Smart Cities in Europe. [online]. Available: http://www.cers.tuke.sk/cers2009/PDF/0103Nijkamp.pdf.

[8]Boyd Cohen. (2012). The Top10 Smart Cities on the Planet. [online]. Available: http://www.fastcoexist.com/1679127/the-top-10-smart-cities-on-the-planet. 